\title{
INVESTIGACIÓN, CIENCIA, TECNOLOGÍA: ¿VER O NO VER?
}

\section{Investigation, Science, Technology: Too See Or Not To See}

\author{
Omar Parra Rozo*
}

Recibido: 21 de julio de 2008 - Revisado: 14 de agosto de 2008 - Aprobado: 2 de septiembre de 2008

El lenguaje de la ciencia pura puede y en rigor debe ser reemplazado por puros y abstractos símbolos, tan impersonales como las figuras platónicas a que hacen referencia.

Ernesto Sábato ${ }^{1}$

\section{Resumen}

La investigación y la ciencia requieren un enlace con diversos los contextos en que se producen. Desde sus elementos básicos de crecimiento: los mitos que las sostienen, hasta los sofisticados desarrollos tecnológicos, no se pueden hacer escisiones que marginen al investigador de lo investigado. Los mitos que se arraigan en el pasado: Prometeo, Hefestos, entre otros, muestran el entrecruce entre la vida diaria, la ciencia y la tecnología, que lanza al hombre hacia el cuestionamiento de su esencia y su relación con el mundo. Se puede afirmar que

* Doctor en Literatura. Magíster en Administración Educativa y Licenciado en Filología y Literatura. Líder de dos grupos de investigación reconocidos por Colciencias: Relaciones, redes y narrativas (Categoría A), Gestión, investigación y narrativa (Categoría B). Correo electrónico: omarparra@ usantotomas.edu.co.

$1 \quad$ Ernesto Sábato es una de las figuras más prominentes de la literatura. Doctorado en Física; abandonó los campos de la mecánica cuántica para dedicarse de lleno a la literatura y la pintura. Preocupado por la comprensión del hombre y su relación con el cosmos, escribió Uno y el Universo, Hombres y engranajes, El escritor y sus fantasmas, Antes del fin y La Resistencia, entre otros ensayos. Sus novelas El túnel, Sobre héroes y tumbas y Abbadón el exterminador, le han valido el reconocimiento mundial como uno de los más grandes escritores del siglo XX. Su deambular temático entre lo visible y lo invisible, entre lo que se ve y no se ve, lo llevo a escribir Informe sobre ciegos, quizás una de los textos más desgarradores sobre la condición humana y la ceguera frente a la realidad. 
la construcción y la reconstrucción de los métodos, los procesos y los productos que conllevan la investigación sólo se pueden entender si se hacen visibles, si se llevan a todos con un lenguaje sencillo y de alcance fácil.

El interés personal, grupal e institucional por el fortalecimiento de los procesos investigativos y por la producción de ciencia hacen que se contemple dentro de los planes de desarrollo el énfasis en la investigación, en el desarrollo de proyectos, en los incentivos y en los productos, pero persisten falencias en la diseminación, la publicación y el desarrollo de materiales informativos y pedagógicos sobre el desenvolvimiento científico, ya sea porque al investigador o al grupo no les interesa la difusión al encontrarse más enfrascados en el método, la comprobación y el resultado que en hacer reconocer lo que investigan o porque no se sabe o no se tiene idea de cómo hacer conocer el producto. Hacer visible lo investigado se constituye en un parámetro imprescindible.

\title{
Palabras clave
}

Visibilidad, diseminar, difundir, mito, invisibilidad, acceso a lo investigado.

\begin{abstract}
Investigation and science require a link with different contexts where they are produced. From their basic elements of growth: myths that sustain them, until sophisticated technologic developments, we cannot make splitting that could marginate the researcher from what he has investigated. According from the last myths in the past: Prometeo, Hephaestus among others, show the crossing between daily life, science and technology that motivates mankind to question his essence with his relation with the world. They can affirm that construction and reconstruction of methods, the processes and the products that involve the investigation could only be understood if they are visible and have a simply language and can be understood by everybody.

The personal, group or organizational concern for reinforcing the processes of investigation and for producing science induce to put into consideration inside the development planning: some emphasis for investigation, for putting in work projects, and incentives and also in new products. However, it exists some lacks in doing the process of dissemination, publication, booklets and pedagogical documents about scientific advances. The cause of this lack is due to an absence of interest of the investigator or group of investigators for diffusion. Maybe the investigator or the group of investigators are more interested in methodology, verification and results than doing public their investigation or they do not know how to do it. Making visible the result of investigation constitutes an obligatory parameter for every research.
\end{abstract}

\section{Key words}

Visibility, splitting, diffusion, myth, knowledge of result of investigation. 


\section{Preludio}

El presente artículo es un producto terminal de la novena fase del Proyecto Investigativo ${ }^{2}$ Institucional, (Proin), del que se han realizado los siguientes trabajos: Gestión, investigación y narrativa: la gestión es cosa de niños; La investigación es un cuento de hadas; La investigación es un placer; Gestión, investigación y narrativa: investigar es un juego; Investigación, docencia y tecnología; Investigar: leer y escribir; La investigación es un placer, Pinocho zaprendiz de investigador?, El tiempo: secreto de la investigación ${ }^{3}$.

Con el propósito de estimular el proceso que emprenden los investigadores y hacer visible la investigación, la búsqueda de la verdad, la difusión, la diseminación de lo investigado se cuestiona la prospectiva de cualquier proyecto, su génesis, desarrollo, culminación y, de manera especial, la caparazón que encierra la ciencia, ocultando las múltiples posibilidades de progreso y la gama de puertas que pueden hacer que lo invisible, lo intangible y el lenguaje cifrado estén al alcance de todos. Escribir y difundir lo investigado ya no es un reto, es una necesidad.

Tanto en el grupo de investigación Relaciones, redes y narrativas, como en el grupo Gestión, investigación y narrativa se trabajan sendos proyectos investigativos que intentan ver los aportes que brindan al proceso de investigación las diversas disciplinas $y$ tópicos del conocimiento, apuntando a una combinación entre lo científico, lo artístico y lo "humano". La desmitificación de un proceso no implica que éste se demerite o se desgaste, por el contrario, se busca el enriquecimiento desde otros puntos de vista y se trata de encontrar la esencia investigativa, propiamente dicha, tanto en el diario transcurrir como en el más complejo proceso investigativo y tanto en los intrincados vericuetos científicos como en los ingenuos y creativos juegos, cantos y cuentos infantiles.

3 Los productos de las cuatro primeras fases, al igual que los productos de la sexta, séptima, octava y novena fases se pueden consultar en los siguientes números de la Revista de investigaciones Hallazgos, de la Universidad Santo Tomás: No. 2, La gestión es cosa de niños (2004); No. 4, Gestión, investigación y narrativa: la investigación es un cuento de hadas (2005); No. 5, Gestión investigación y narrativa: investigar es un juego (2006); No. 6, Investigación, docencia y tecnología (2006); No. 7, Investigar: leer y escribir, No. 8, Pinocho iaprendiz de investigador? (2007) y No. 9, El tiempo: secreto de la investigación (2008). El producto investigativo de la quinta fase se puede consultar en el artículo La investigación es un placer (2007), publicado por la Revista Aquichán de la Facultad de Enfermería, Universidad de La Sabana (Año 7, Vol.7, No. 111-112).

\section{La infancia de la ciencia y de la tecnología}

Bien cabe decir en este aparte que la ciencia y la tecnología son ajenas al infante y que, en el sentido estricto del término: infancia, hay una clara referencia al que no habla, al que no tiene nada que decir. Desde que el profesor John Dewey se quejaba de que el colegio no le daba al niño los elementos suficientes para apropiarse de la vida, en especial los materiales, las herramientas, los laboratorios, las técnicas, hasta que Carl Sagan, un monstruo de la investigación, trató de poner la ciencia al alcance de todos, pasaron muchos años de discusión y de malos entendidos. Todavía ocurre que los currículos de las instituciones educativas no tienen la suficiente esencia científica o tecnológica para llevar al aprendiz a apropiarse del mundo de una manera racional. A los padres les asusta que algunos profesores pongan al alcance de la mano de sus estudiantes algún telescopio que penetre las profundidades del espacio y abra los ojos y la mente a las discusiones sobre la composición del universo o a las simples preguntas formuladas por un niño, que presentan gran dificultad para su respuesta por parte de un adulto: ipor qué la Tierra es redonda?, ¿por qué los planetas giran alrededor del Sol? $\mathrm{O}$, sencillamente ipor qué se dice que el Sol sale y se pone y no que la Tierra sale y se pone? Con todas las implicaciones copernicanas, newtonianas y keplerianas que pueden conllevar las correspondientes repuestas.

El problema de socialización y visibilidad de la ciencia se vive desde los primeros años de educación y se puede decir, sin temor a equivocación, que hay un miedo profundo al conocimiento y a acercarse a la verdad. Un temor que no sólo se transmite a los niños, sino que también se arraiga en las personas mayores. No se quiere ver la ciencia, ni apropiarse de ella, ni transmitirla, ni aprenderla, ni introducirse en su mundo; todavía se consideran como bichos raros o como seres sobresalientes, en la mayoría de las instituciones educativas, a los profesores o estudiantes que incursionan en los campos de la robótica, de las máquinas voladoras, subacuáticas o terrestres, cuando esta inmersión debería ser un hecho cotidiano, un 
elemento constitutivo del quehacer educativo, si es que de verdad se está sumergido, o se quiere estarlo, en el mundo de la tecnociencia.

La Asociación Americana para el Avance de la Ciencia (American Association for the Advancement of Science) de los Estados Unidos (AAAS), organización internacional, cuyo propósito primordial apunta al progreso de la ciencia en el mundo y a hacerla visible y viable, publica entre sus diversos materiales, libros y reportes, la revista Science, la cual constituye un referente obligado para tener un acercamiento al desarrollo y al entendimiento del mito moderno que envuelve a los científicos y que en su madeja arrastra a todos los habitantes del planeta, quiéranlo o no, sean conscientes o no de ello. Desde que la revista fue fundada por Thomas Alva Edison en 1880 hasta nuestros días, sus páginas han visto pasar grandes constructores y difusores de la ciencia como Albert Einstein y Edwin Hubble, entre otros. Para la conmemoración de su aniversario 125, la revista tuvo a bien seleccionar y comentar veiticinco preguntas, de otras 125 susceptibles de ser respondidas en los siguientes veinticinco años de su formulación (2005). Entre dichos cuestionamientos cabe destacar: ¿cuál es la base biológica de la conciencia? ¿Por qué los humanos tienen tan pocos genes? ¿Cuánto más se puede extender la expectativa de vida humana? (Science, 2005). Dudas y controversias que bien pueden ser el origen o el culmen de múltiples investigaciones y que personas de diversos niveles de estudio, desde las analfabetas, hasta los investigadores más avezados pueden llegar a no conocer jamás.

Tal y como lo afirmó el investigador Fernando Cajas (AAAS), a principios de esta década (2001) el problema de la diseminación de la investigación y de la ciencia es un problema de "alfabetización científica y tecnológica", un problema de "trasposición didáctica del conocimiento científico". Si el mito de la ciencia se ha adentrado en nuestros rincones más privados y hace parte de nuestro pensar, sentir y actuar, es necesario que haya una apropiación de éste, la cual debe empezar en los primeros años y se debe incrustar en los currículos y en los diversos planes de estudio de las instituciones educativas, no sólo como parte de la formación y de la vida, sino también con el propósito de su difusión, su divulgación y socialización.

El reto no es fácil, pero es evidente vislumbrar que la misma transformación generacional lleva a ello, que existe un "atosigamiento científico", que los padres y los maestros no saben qué hacer con los nuevos aparatos cotidianos como el iPod y con los demás derivados tecnológicos. Consecuentemente, se ignora cómo "bajar música", repartirla, adicionar elementos a su composición, a sus sones, palabras y mensajes; los ejemplos se pueden multiplicar: los video juegos, con sus variadas innovaciones tecnológicas, gráficas y de sonido; los televisores con multiplicidad de funciones, las cámaras fotográficas programadas para captar la risa, centrar los acontecimientos, los grupos, en suma, los diversos adelantos, ajenos e incomprendidos, cada día más, entre una generación y otra.

Y no solamente enfrentamos el problema de la formación del niño, del adolescente y la brecha generacional, sino que también nos encontramos inmersos en un universo informativo que cada día es menos nuestro por algunas razones esenciales, entre otras, porque no hay una suficiente conciencia en las instituciones donde se produce ciencia y se investiga, porque aún se cree que dicha actividad es de algunos genios que saben hacerla, de profesores que se dedican altruistamente a investigar, de docentes que requieren un complemento a su trabajo o de decisiones gubernamentales que no contemplan en sus planes la ciencia, la tecnología y la investigación, como elementos fundamentales del progreso y la supervivencia. Los seres humanos se encuentran en los albores de la ciencia, el temor por adentrarse en el universo de los datos, del conocimiento y de sus aplicaciones es profundo y se enraíza creando un caparazón que aísla. La brecha que se abre entre el que sabe y el que no sabe, entre la sociedad que conoce $y$ la que no conoce se hace infranqueable. 
Los planes que alguna vez tuvo la lechera ${ }^{4}$, son los mismos con los que tratamos de abordar el conocimiento, la ciencia. Hacemos castillos en el aire, ilusiones sobre proyectos, creemos que la ciencia y la tecnología están encerradas en una urna herméti$\mathrm{ca}$, en la canastilla del quinto hermano del barbero cristal, engañado en Las mil noches y una noche por sus sueños, por su visualización de un futuro mejor, truncado por su vuelta a la realidad, en el momento exacto en el que de una patada hizo trizas el canasto ${ }^{5}$ donde guardaba la fortuna de cristales que en el futuro le iban a suministrar la mejor esposa y los más grandes bienes de la tierra. Verdaderos infantes que tratamos de incursionar en el mundo de la ciencia, tenemos mucho que decir, que soñar y que hacer, sin romper la canastilla del hermano del barbero, ni la olla de miel de doña Truhana y, mucho menos, el cántaro de la feliz lechera.

\section{La ciencia y el mito}

Parecería que el mito que más identifica la ciencia, la investigación y la tecnología es el de Prometeo; no obstante, se pueden encontrar otros relatos como los de Epimeteo, Hefestos y Cronos, Ios cuales también aluden a hechos y leyes generales que rigen el mundo, protagonizados por personajes de origen divino.

La ciencia, tan eterna y tan efímera, unas veces se detiene y otras avanza a velocidades fantásticas. En

$4 \quad$ La fábula de la lechera se ha extendido por el universo literario como el símbolo de lo que se pretende hacer, de lo que se sueña y se hace imposible frente a la realidad contundente. Esta enseñanza que viene arraigada desde los relatos orientales más antiguos fue conocida gracias a las versiones de las Mil noches y una noche. Esopo en el siglo VI la condensó en una versión que más tarde fue adaptada y cambiada en algunas partes. El infante Don Juan Manuel (s. XIV) la puso en boca de doña Truhana y la versión más difundida desde el siglo XVIII es la de don Félix María de Samaniego.

5 La historia de El-Aschar, quinto hermano del barbero constituye, no solamente una narración antecesora de la fábula de la lechera, sino también una advertencia para los investigadores que pretenden solamente soñar sin llevar a cabo sus proyectos y sin tener los pies puestos en la realidad: "Y mi hermano hizo ademán de dar puntapié a su soñada esposa y lo dio de lleno al canasto que encerraba la cristalería. Y el cesto salió rodando con su contenido. Y se hizo añicos todo lo que constituía la fortuna de aquel loco" (Las mil noches y una noche, 1978, p. 205). cualquiera de los dos casos, lo más cruel y desesperante, tanto para quienes trabajan con ella, como para sus usuarios, es ver que sus productos, se desgastan, se vuelven inútiles, se deslizan entre los dedos. Las premisas de Heráclito: todo cambia, todo se transforma, "todo fluye", nada vuelve se hacen patentes. La ciencia se constituye en una forma extraña de existir, un mito en sí misma que obliga a sus creyentes a vivirlo con la certeza de su valor volátil. ver y no ver se plasman claros y patéticos.

Si nos supeditamos a la narración maravillosa que constituye un compendio de conocimientos ahistóricos y hace referencia a la génesis del mundo, al trajinar de sus dioses, a los hechos divinos que explican los fenómenos como el amor, el odio, la guerra, la paz, en suma, si vemos que a través de un mito se condensa una "realidad humana de significación colectiva y universal", con unos leves cambios, podremos adaptar esta definición a la concepción científica, a la reseña simple del DRAE, al "Conjunto de conocimientos obtenidos mediante la observación y el razonamiento, sistemáticamente estructurados y de los que se deducen principios y leyes generales". Enfrentados a un nuevo mito, los seres humanos, tratan, como antaño, de explicarlo, de sentirlo y -quiéranlo o no- de vivirlo, de estar dentro de él, de ajustarse a sus leyes e, inclusive a sus caprichos: iquién ignora la existencia de herramientas tecnológicas como los computadores, los teléfonos celulares, los innumerables aparatos que llenan los hogares, laboratorios, universidades y que en aras del progreso pueden llevar a la destrucción del ser humano?; ¿quién está apartado de las mínimas reflexiones sobre las profusas investigaciones del calentamiento global, las epidemias mundiales y los múltiples fenómenos derivados de las explicaciones científicas, originados por sus adelantos o simplemente estudiados por la ciencia?

En su Breve historia de la filosofía, el profesor Johannes Hirschberger, al examinar a los presocráticos que, según los estudiosos, son los generadores de la filosofía y de la ciencia, dio una definición de los pitagóricos como los primeros pensadores que introdujeron en 
el pensamiento griego la idea del orden y la armonía, tan caros a los científicos actuales:

Las formas que ordena el ser no surgen caprichosamente, sino que constituyen un sistema, un todo que tiene sentido, una armonía cósmica. "Todo el edificio celeste es armonía y número". "Los sabios enseñan que el cielo y la tierra, los dioses y los hombres forman comunidad, con amistad, orden, medida y justicia, por lo cual a todo esto llaman cosmos". Con razón se ha dicho que el descubrimiento pitagórico es uno de los más vigorosos impulsos dados a la ciencia humana (Hirschberger, 1977, p. 19).

Un orden y una armonía que suponen un origen. En el principio era el caos, puede ser la primera enseñanza de un mito o puede ser la premisa inicial de una investigación científica. En su Introducción a la ciencia, Isaac Asimov postula que el principio no es el verbo ni la acción, ni la explosión, es, sencillamente la curiosidad; de esta manera pone a los animales más curiosos como aquéllos que pueden sobrevivir en un contexto adverso:

El individuo que vacilaba en la lucha competitiva por los alimentos, que se mostraba excesivamente conservador en su exploración, simplemente perecía de hambre. Tan pronto como ocurrió eso, la curiosidad sobre el medio ambiente fue el precio que se hubo de pagar por la supervivencia (Asimov, 1985, p. 13).

Con certeza se puede afirmar, desde la génesis mítica, que los griegos y el mundo occidental se supeditaron al terrible Cronos, al tiempo que todo lo destruye, a la entidad que eliminaba -devoraba, exactamente- a sus hijos. Aunque nadie podía resistirse a su destino fatal, el creador invencible fue derrotado por la sapiencia suprema, por la inteligencia divina, por el saber, por la ciencia -si se puede usar este término-, en suma, por Zeus, el dios de la sabiduría, de todos los dioses y de todo lo conocido. En la lucha entre el tiempo y el conocimiento también ganaron otras divinidades: el amor, la paz, la belleza, el orden, la guerra y las múltiples deidades que representan la vida y el quehacer humano.
Agazapado en algún rincón, Prometeo, el reivindicador de la raza humana, se apoderó del fuego, máximo tesoro de los dioses, don preciado del inaccesible Zeus y lo entregó a la raza humana. La sabiduría y la insaciable curiosidad pasaron a manos de los hombres, quienes, desde ese momento, las hicieron suyas, las mantuvieron, las trataron de alimentar, se acercaron a las leyes que gobiernan el universo, inventaron instrumentos y herramientas diversas para gobernar lo conocido $y$ quisieron ser como los dioses.

En la Tierra, Heráclito no podía ocultar su regocijo; de mil maneras propagó al mundo que el fuego era el origen de lo creado y que el devenir, dominado por la medida, por el control -como lo quieren los científicos- está supeditado al debate, a la controversia y a la dialéctica. Heráclito, el antecesor, tendría eco por los siglos de los siglos hasta Newton, Galileo, Kepler, Einstein, Feynmann, Dyson y muchos más. Todo lo creado, todo lo que existe, se transforma, lo dijo maravillosamente el filósofo presocrático y lo puso a nuestros pies Borges, creando y recreando su constante del cambio, del otro, de lo que nunca para, de "los insensatos párrafos que ceden las albas a su afán", del inexorable tiempo, del divino Cronos que, a pesar de la ciencia y de sus esfuerzos por dominarlo, inescrutable persiste, todavía vive, más que nunca y, siempre eterno y victorioso, nos supedita a su albedrío.

Retornando al mito, una vez que el saber había sido sustraído, sus poseedores, los dueños del conocimiento tenían que recobrar y mantener su tesoro -como siempre- $y$, por lo menos, castigar a la deidad que se había apoderado de la sabiduría y se la había entregado a los hombres (Prometeo, el usurpador). Precisamente, uno de los encargados de apresarlo y de torturarlo fue, naturalmente, el dios de las herramientas, de los instrumentos, Hefestos. Y como de mitos se trata, no se puede dejar de lado que la divinidad deforme tenía como atributo el fuego, con las connotaciones de fuerza, propagación e impacto que el elemento tenía, pero estaba muy claro que la deidad era un intermediario, el símbolo de las herramientas 
de la tecnología y como tal, no estaba a la altura de los otros dioses aunque lo intentara.

Siendo así, Hefestos, el dios de la forja, de los herreros y los artesanos, de los hombres que manipulaban los instrumentos y el fuego para ser superiores a los demás y a la misma naturaleza, tenía el poder de la tecnología en su mano y sabía muy bien qué hacer con él: dominaba las artes de la guerra, lo ostentó en la llíada; descifraba los senderos del conocimiento y de la ciencia, lo interpretó muy bien en su relación con Atenea; podía reinar en el hogar, lo demostró al intercambiar ideas con Hera. En el combate lució su destreza al dotar de las mejores armas al hijo de los dioses, el divino Aquiles. En el amor fue el dominador de Afrodita y en la guerra pudo vencer al temible Ares. Era evidente que con la tecnología todo se podía lograr y que los instrumentos que día tras día inventara el hombre, en algún momento, podrían vencer al conocimiento.

Desde aquellos tiempos ancestrales un miedo se apoderó de los científicos, un temor que se transformó en móvil y en reto: la probabilidad de que la tecnología, los instrumentos y las máquinas dominaran al mundo. Muchos siglos después, dicho pavor encontraría eco en Asimov y sus seguidores y bien podría estar fundamentado en una narración mítica con pretensión de ser premonitoria: La última pregunta ${ }^{6}$, que formula un ser humano, en el cuento del mismo nombre, después de tener la plena seguridad de que la ciencia, la técnica y la máquina han llegado a dominar el Universo: “¿Es el fin? -preguntó el hombre. ¿No se puede revertir este caos para recobrar el universo? ¿No es posible?" (Asimov, 1994, p. 506).

Definitivamente los griegos que todo lo inventaron y todo lo previeron, se habían anticipado al dominio de la ciencia y de la tecnología sobre el hombre. Finalmen-

Isaac Asimov, deambulando entre sus ensayos científicos, sus producciones de ciencia ficción, sus elucubraciones filosóficas y sus contundentes narraciones, se aventuró a mostrar cómo la máquina, absolutamente perfeccionada por el hombre y por ella misma puede llevar a la destrucción de lo creado y originar un nuevo comienzo. te, éstas lo harían su esclavo y para su liberación no valdría ningún enfrentamiento, fuerza o conocimiento $y$, mucho menos, algún sentimiento.Al final, Hefestos ganó su batalla tecnológica, los instrumentos empezaron a dominar el mundo. Zeus, danzante en su trono, sabía muy bien, que quien domina el conocimiento, el saber, la información, lo domina todo. Al final de la confrontación de los dioses, los hombres, más allá de la liberación prometeica, son instrumentos útiles de la alegoría que ha dominado los últimos siglos, quizás del último mito: la ciencia. Ahora, todos insertos en la organización científica, debemos propagar su conocimiento o no sobreviviviremos, mantenemos su estado y su ser o no avanzaremos. Fatal condena, unos creadores que quisieron pensar, sentir, hacer y expresar sólo podrán realizar lo último y con ciertas condiciones. El águila que cada día devora a Prometeo sigue picoteando y aunque el dios renueva su organismo, por ser inmortal, está condenado a la fatalidad.

El físico británico Colin Bruce 7 , otro investigador que pretendió llevar la ciencia a un plano sencillo y entendible, con paralelos y ejemplos sobre la existencia de muchos mundos, trajinó con múltiples teorías y científicos, mostrando problemas y experimentos que pretenden acercar a cualquier persona desprevenida a la concepción del cuanto, de la física y de los universos paralelos. En palabras del físico Michio Kaku, Bruce

Colin Bruce es un físico matemático que ha dedicado su vida a demostrar científicamente que existen mundos paralelos, que el mundo cuántico subatómico constituye una certeza y que tratamos de ignorar -como se ha hecho desde siempre- aquello que no se ve, se palpa o se siente. Las numerosas interpretaciones de la realidad permiten concebir tecnologías inimaginables y Bruce quiere mostrarlas, bajar al plano "humano" las concepciones que han hecho que los físicos "compartan información entre mundos, y ordenadores que pueden utilizar el poder de otros mundos para efectuar cálculos". Sus planteamientos no tienen una vara mágica, ni un postulado de ciencia ficción; sus afirmaciones e interrogaciones plantean una mirada diferente: "Enfocar un problema desde un punto de vista nuevo ofrece la posibilidad de entender aspectos inéditos del mismo, y los problemas que plantean las viejas interpretaciones del cuanto constituyen posibilidades muy valiosas". Su pregunta investigativa básica proporciona una idea de su trabajo y de lo que pretende demostrar: ila extrañeza del mundo cuántico indica la existencia de un problema profundo a nivel teórico?" (Bruce, p. 11). Entre sus obras se puede contar con Los conejos de Schrödinger, La paradoja de Einstein y otros misterios de la ciencia resueltos por Sherlock Holmes y Conned Again, Watson! Cautionary Tales of logic, Match and Probability. 
intentó introducirnos en el "estimulante viaje a la Dimensión desconocida de la teoría cuántica". Dentro de la corriente que alimentan diversos teóricos y profesores, a fin de mostrarnos la ciencia, de hacerla visible y, más que ello, comprensible, plasma en sus escritos, ejemplos, anécdotas y arquetipos con extraterrestres, situaciones imaginarias, cuentos infantiles, anécdotas disparatadas, para que seamos capaces de palpar, vivir y aprender la física, las probabilidades del cálculo, la simple segunda ley newtoniana: "La fuerza que actúa sobre un cuerpo es directamente proporcional al producto de su masa y su aceleración: $\mathrm{F}=\mathrm{m} \cdot \mathrm{a}^{2 \prime \prime}$.

Si en los siglos anteriores existía un marcado interés por encontrar cosas nuevas, por revisar los postulados y lanzarse al planteamiento de diferentes paradigmas e inventos, de herramientas que hicieron de la tecnología una dependencia, ahora se ha ido construyendo un nivel de gestión que supone adaptarse a los nuevos contextos y a los horizontes difusos, en los cuales la búsqueda de recursos para investigar, para hacer ciencia, junto con la administración de éstos, el impacto de los productos investigativos y científicos, tanto en la sociedad, como en los currículos educativos y en la ciencia misma se constituyen en un bumerán. Paralelamente al crecimiento incontrolable del mito científico, surge un aditamento: el mito y la ciencia misma no pueden caminar si los seres que viven de ello no conocen los productos, no saben de los procedimientos y métodos, no participan de las preguntas, no comunican a los demás los resultados que se obtienen. Hacer que se conozca lo que se produce se volvió un requerimiento para avanzar en el camino científico. Hacer que se vea, que se valore, se reconozca, se critique, se revalúe lo planteado -o se consolide- se ha convertido en una consigna. La visibilidad, dentro de la investigación, la ciencia y la tecnología, se trocaron en una necesidad primaria: se muestra lo que se inventa, so pena de no sobrevivir.

\section{Visibilidad y locura}

Si en el Renacimiento teníamos el arte como referente, como forma visible de ver la vida, racional, con una concepción de belleza que recuerda a Protágoras y al hombre como medida del mundo, en la actualidad, la locura de Dalí, el artilugio de Picasso, las posturas de Einstein y Feynmann, las protuberancias de Botero, las investigaciones de los múltiples físicos actuales, el diario trabajo de la búsqueda de la verdad de nuestros docentes y estudiantes desbordan el antropocentrismo y confluyen en unos inquietantes cuestionamientos: ¿y nosotros qué?; ¿cuál es nuestro papel?; ¿cómo hacernos ver, notar?; ¿ cómo mostrar nuestros productos, nuestra investigación, nuestra ciencia? Y con mayor medida ¿cómo hacer que lo que investigamos o descubrimos se conozca y llegue a todos?

Al hacer referencia al mito griego que trata de mostrar la génesis de la ciencia, también se puede buscar la relación más íntima del pensamiento con el origen del trabajo, del hombre, del arte y de los artesanos. Cada vez que se profundiza en las narraciones, en las visualizaciones griegas, los estudiosos encuentran más explicaciones a las diversas situaciones y hechos actuales, en la paz y en la guerra, en el conflicto, en la democracia y en la tiranía, en fin, en los diversos temas y, particularmente, en los que nos atañen, la visibilidad y la invisibilidad. El profesor e investigador francés, Jean Pierre Vernant ${ }^{8}$ mostró como para los griegos era sumamente importante lo que había exis-

\footnotetext{
Jean Pierre Vernant, filósofo e historiador francés, fundador del Centro de Investigaciones comparadas sobre las sociedades antiguas (Centro Louis Gernet), participó activamente en los estudios sobre mitología, política, religión y ciencia griegas. Consideraba que el hombre era un puente entre lo que se ve y lo que no. Su tema recurrente del coloso, del elemento que une la vida y la muerte, lo creado y lo no creado, le hizo afirmar: "Nuestro estudio sobre el colossos y la categoría psicológica del doble, debe leerse como una primera contribución a una investigación más extensa que corresponde a la aparición de la imagen en sentido propio, a la aparición de una actividad creadora de imágenes" (Vernant, p. 20). Murió bordeando el centenario, a los noventa y tres años (2007), dejando una estela como héroe de la resistencia francesa, en la Segunda Guerra Mundial y como defensor y difusor del pensamiento griego. Entre sus obras se puede contar con Mito y pensamiento en la Grecia Antigua; En el ojo del espejo, Érase una vez...El universo, los dioses, Ios hombres. Un relato de los mitos griegos.
} 
tido, existía y permanecía, aún en el recuerdo y en la vivencia. Nada de lo realizado o de lo que pasa se puede dejar de lado; de alguna forma tiene que subsistir, así sea en el recuerdo o en el sueño. Vernant acudió a una extraña vivencia de Aquiles, en la Ilíada, quien tras una noche de duelo, percibe a Patroclo con sus mismas ropas, sus armas y su halo personal. El héroe griego trata de abrazar a su amigo y éste se desvanece como el vuelo de un pájaro. Luego en su escrito La categoría psicológica del doble hizo más patente la relación entre el hecho y lo que se siente frente a él, lo que se escribe, lo que se plasma. Con unos rápidos comentarios sobre varios mitos, como el de Helena y el de la Gorgona, hizo ver la importancia de proclamar lo existente, de hacer ver que lo invisible existe, que tras el hecho hay algo que debe ser comunicado, sentido, expresado, vivido. Al hacer alusión al signo religioso, al ritual de hacer visible lo invisible, manifesó que éstos lenguajes no tienen como "objeto solamente evocar en el espíritu de los hombres el poder sagrado al que remite; también quiere siempre establecer con él una verdadera comunicación, insertar realmente su presencia en el universo humano" (Vernant, p. 315).

Muchos siglos después de los griegos, llevando a cuestas sus enseñanzas y sus formas de ver el mundo, científicos como Nicolás Copérnico, Galileo Galilei, Johannes Kepler, Isaac Newton y Albert Einstein, entre otros, conformaron un grupo que vio el cosmos como un todo organizado con unas leyes, aparentemente invisibles, que el ser humano va develando poco a poco. Por ejemplo, Johannes Kepler constituyó una de las muestras más palpables de hacer visible lo invisible; su profunda convicción de que el método de la observación, la teoría y la experimentación debían ser "vistos", palpables, reconocibles en su tiempo o después, lo llevaron siempre a consignar lo que veía, a tratar de hacerlo llegar a un público. Consideraba este deber como un mandato divino.

Por su lado, Stephen Hawking, el notable físico inglés, obsesionado por mostrar la ciencia, por hacerla visible, dijo que: "Si alguna vez se otorgara un premio a la persona que a lo largo de la historia más se ha obstinado en la búsqueda de la precisión absoluta, éste podría obtenerlo el astrónomo alemán Johannes Kepler" (Hawking, 2004, p. 101).

Y respecto del mencionado científico germano que cambió el orden arbitrario del universo para acercarlo al orden divino, del mismo que consignaba lo que veía, lo que experimentaba y que quería darlo a conocer e intercambiar ideas con los demás investigadores, de aquél que era consultado por Galileo, Hawking trae un fragmento del Libro Quinto de Las armonías del mundo, en el cual Kepler que creía haber encontrado la lógica de Dios en la creación del universo, muestra la importancia de escribir, de hacer visible lo encontrado, de mostrarlo al mundo, no importando en qué momento pueda ser leído:

\begin{abstract}
Me atrevo a confesar con franqueza que he robado los vasos de oro de los egipcios para construir un tabernáculo para mi Dios muy lejos de los límites de Egipto. Si me perdonáis por ello, me alegraré; si me lo reprocháis, lo soportaré. La suerte está echada, y escribo el libro para ser leído ahora o en la posteridad, no importa cuándo. Puede esperar más de un siglo a su lector, tal como Dios ha esperado seis mil años para encontrar mi testimonio (Hawking, 2004, p. 112).
\end{abstract}

De la misma manera, al referirse a la escritura y a la necesidad de comunicar el conocimiento, de difundirlo, diseminarlo, Hawking, con su humor maravilloso, dijo que él mismo "ha vendido más libros sobre astronomía que Madonna sobre sexo", refiriéndose primordialmente a su Breve historia del tiempo, de la cual vendió más de ocho millones de copias. El físico inglés en una de sus obras, seleccionó a cinco monstruos que a su juicio son gigantes, subidos unos encima de otros, aludiendo a la interdependencia necesaria en la ciencia y en la investigación y a la frase célebre de Newton en su carta a Robert Hooke en 1676: "Si he logrado ver más lejos, ha sido porque he subido a hombros de gigantes" (Hawking, 2004, p. 9).

Influenciado por la pasión de llevar la ciencia a los niños, de ponerla al alcance de un grupo común, junto con su hija Lucy, acaba de ofrecerle al mundo una de varias obras que tiene pensadas con la finalidad de 
popularizar la astrofísica: George y su llave secreta del universo. Así como Hawking acude a estos medios impresos para divulgar el conocimiento, otros investigadores acuden a las cartas, los mensajes, las revistas, los artículos, los documentales, las medios digitalizados y a otras formas de diseminación, de mostrar lo que se trabaja, de nombrar lo innombrado.

\section{Horizonte e imaginación}

En los últimos años ha habido un interés especial por el fortalecimiento de los procesos investigativos y por la producción de ciencia. En particular, las universidades contemplan dentro de sus planes de desarrollo el énfasis en la investigación, en el desarrollo de proyectos, en los incentivos, en los productos, pero existe un campo fértil y no suficientemente explotado, el de la diseminación, la publicación, el desarrollo de materiales informativos y pedagógicos sobre el desenvolvimiento de la ciencia y de la investigación. Las consultas con los bibliotecarios, los docentes, los investigadores y los mismos estudiantes arrojan que hay poco bagaje en la acumulación, ordenamiento y generalización de lo científico. No es que no se haga ciencia o que no se tengan procesos mínimos, es que no se conocen; un investigador o un grupo trabaja y no puede mostrar su producto por diversas razones: unas porque no se fija ni detalla en su proyecto que se debe realizar esta actividad; otras, porque al científico o al grupo no les interesa la difusión, se encuentran más enfrascados en el método, la comprobación y el resultado que en hacer reconocer lo que investigan; unas más, porque no se sabe o no se tiene idea de cómo hacer conocer el producto, ya sea porque se dificulta condensar en un material impreso o virtual lo que se ha realizado o, sencillamente, porque no se contempla este aspecto. El horizonte es difuso.

Si alguna vez se hablaba de la torre de marfil en las que se encerraban los investigadores, hoy se puede hablar del cuarto oscuro que dificulta que la foto se revele o que facilita que se realice el proceso, pero el fotógrafo no lo sabe.
Ahí está el producto ¿qué hago con él?; ¿dónde lo pongo?; icómo hago que se conozca? Las respuestas parecerían triviales, pero no lo son; cualquier investigador puede indagar y las respuestas son confusas. El simple hecho de poner un artículo a discusión para una posible publicación en una revista indexada es, de por sí, una odisea. No hay facilidades para acceder a los órganos informativos. Muchos escritos, producto de investigaciones complejas son rechazados por no cumplir con unos indicadores mínimos para su publicación. La culpa del rechazo no es de quien lo recibe, aquí se cumple con unos requerimientos básicos, si no se dan, el posible artículo no pasa. Tampoco tiene la culpa quien lo envía, probablemente no acató algún requisito formal. La madeja envuelve y borra el horizonte. Se puede perder el resultado de una investigación, se puede archivar un proceso e incluso se puede invalidar.

Al planteamiento anterior se une el problema de la credibilidad; no es lo mismo un artículo o un producto proveniente de un país altamente desarrollado, cuyas instituciones tienen validez, sin cuestionamientos, que de un país sin reconocimiento, cuyos productos, de por sí, son infravalorados, amén, de que los investigadores tratan de publicar en revistas con algún reconocimiento internacional y en un idioma (inglés) que, muchas veces, les es desconocido y que, a fuerza de costumbre y de dominio se ha impuesto en el ámbito científico. No hay que profundizar demasiado en este entorno, el sentido común, el diario trajinar y las múltiples investigaciones, como la de Leslie Chan, Barbara Kirsop y Subbiah Arunachalam (2005) confluyen en la conclusión manida en nuestro medio que las publicaciones sobre productos científicos recaen en las naciones más desarrolladas, encabezadas por Estados Unidos, campo en el que se puede afirmar que el $80 \%$ de las publicaciones especializadas se produce en estos países, a lo que se suma el alto costo de producir y acceder al conocimiento especializado.

Los seres humanos tienden a construir modelos, formas de representar la realidad, mapas simples y complejos, maneras de entender el mundo, adaptarse a él, 
transformarlo y sobrevivir. Desde la comunicación más elemental, una mirada, una sonrisa, un saludo, hasta los comportamientos complejos, el enamoramiento, el trabajo, la producción artística, la labor formativa, el producto científico y las demás actividades que circunscriben la vida, se exige un patrón de referencia, un manejo común de lenguaje que hace que los hombres se entiendan, conozcan, comprendan, analicen, sinteticen, den juicios de valor, apliquen sus saberes, transformen su medio. Detrás de todo ello, un cúmulo de creencias, de narraciones, historias y experiencias acumuladas se convierten en el medio de comunicación. Así, el mito, la leyenda y las narraciones maravillosas que escapan al espacio y al tiempo tratan de mostrar el origen del mundo y los acontecimientos que marcan el devenir de la humanidad.

\section{Leer, ver y aprender}

En otro artículo que escribí: La lectura y la escritura, hermanos siameses de la investigación, traté de defender las premisas primordiales con las que se aprende, se investiga y se hace ciencia: leyendo y escribiendo, indagando y experimentando; en todo caso, siempre buscando la verdad (Parra, 2008, pp. 209-236).

En la actualidad se suele hablar mucho de la visibilidad, del reconocimiento, de la acreditación del conocimiento, su estudio, enseñanza y difusión. Se organizan investigaciones, cuyas conclusiones pretenden mostrar los mejores investigadores y productos en determinadas disciplinas; los mismos premios, entre ellos el Premio Nobel, destacan los grandes logros y muestran el avance y el progreso de la ciencia. Los rankings o las clasificaciones que valoran unos productos, que en últimas dicen muchas cosas y no dicen nada, pretenden indicar, de alguna manera, los grados de visibilidad, nos señalan quién está adelante, quién se encuentra rezagado y quién ni siquiera está dentro de la clasificación. Pero quien verdaderamente marcha a la vanguardia, es quien incide en la sociedad, la hace comprender, la marca, coadyuva su transformación, brinda pautas de orientación, de dirección, de alguna manera traza su deambular.
Eran otros tiempos cuando el inventor y mecenas Thomas Alva Edison reunió más de mil patentes. Ahora, es tan difícil lograr una sola, como difícil encontrar, situar y lograr la valoración de un artículo científico, el reconocimiento de una publicación. Se hace más sencillo alcanzar, en ámbitos no científicos, la no irrisoria suma de más de cien millones de libros vendidos y producidos por cerca de sesenta editoriales de Paulo Coelho, un autor, cuyos manuscritos se compran antes de ser escritos, según lo expresó Jürgen Boos, director de la Feria del libro de Francfort (Salazar, 2008, sección 3, p.1).

La divulgación de la ciencia no es fácil, sin embargo, se pretende imponer como una obligación, de hecho ya lo es. Si era espinoso mostrar el conocimiento, enseñarlo, conducir a las personas a que lo amaran, ahora, difícilmente se puede llevar a que se difunda, a que se conozca, máxime si en el ambiente deambula el monstruo tentador de copiar y pegar, del facilismo en el aprendizaje, de la popularización informativa, del desborde de los derechos de un autor que trajina con un experimento y una temática toda su vida, frente a la premisa de que el conocimiento es de todos y para todos.

Jennifer Ouellette, miembro de la Sociedad Estadounidense de Física (APS), ha dedicado toda su vida a encontrar lectores y aprendices de Física, sin mayores resquemores y sin el miedo de abordar una temática incomprensible para el público común. Como bien lo dice Alan Chodos, ejecutivo asociado de la APS, desde que Jennifer comenzó a escribir una columna, titulada Este mes en la historia de la física, se han popularizado los temas en la escuelas y universidades norteamericanas haciendo ver las bondades y las facilidades de acercarse a procesos tales como el efecto mariposay la teoría de las cuerdas sin mucho aspaviento. Defensora de la divulgación científica, miembro de la Asociación Nacional de Escritores científicos propugna por que se difundan sus artículos, que vayan más allá de revistas como Discover, New Scientist y Salon. En su libro Cuerpos negros y gatos cuánticos es fácil entender el principio de incertidumbre de Heisenberg de la 
misma manera como la paradoja del gato cuántico de Schrödinger, que tanto ha cuestionado a los físicos y a los filósofos, incluyendo al mismo Hawking.

En el prefacio, Ouellette se queja de la profunda brecha que ha aparecido entre el arte, la ciencia y las humanidades; manifiesta que esto no puede ser, pero de hecho se ha dado. Al aludir a los filósofos de la naturaleza, tan íntimamente ligados a la ciencia, la filosofía, las matemáticas y la vida, no puede menos que quejarse de la división actual, algo que no entendería en medio de su genialidad un inventor como Leonardo Da Vinci:

Perdimos la noción de unidad en alguna parte del camino. La ciencia y las humanidades son percibidas, a menudo, como polos opuestos, o como líneas paralelas (o universos) que nunca se juntarán. No obstante, ahora más que nunca, la física está moldeando de modo irrevocable nuestros conceptos del tiempo, el espacio y el lugar que ocupamos en el universo. Y esto la vuelve pertinente no sólo para los especialistas en ese campo, sino para todos (Ouellette, 2007, p. 20).

Para entender un poco, la profunda división entre los lenguajes exactos y los lenguajes de las humanidades es necesario hacer un poco de historia. Remontarse a los primeros escribas o a las primeras personas que tenían por función poner sobre un material la interpretación que se tenía del cosmos, supone adentrarse en el corazón de algunos pueblos primitivos como los babilonios, por ejemplo, quienes poseían una astronomía muy desarrollada, integrada a una religión y a una economía. El escriba tenía que contar lo que pasaba en el cielo y lo que sucedía dentro de su ciudad para que el rey con estos datos pudiera tomar sus decisiones y realizar sus ritos. Profundizando en este tipo de escritura y en la interpretación astronómica se puede deducir que su carácter era estrictamente aritmético, así, la posición de los astros y la predicción de los fenómenos serían anotadas en tablillas y calculadas exactamente. Los griegos toman este saber y lo cambian, su modelo es espacial, geométrico y se desligan, en un principio de la religión cósmica, tratando de explicar los hechos y los fenómenos desde una íntima relación con la naturaleza (Vernant, s.f., pp. 183-187). Dada la ruptura varía el paradigma.

En este punto cabe resaltar la importancia de la escritura y de la comunicación. Martin Gardner, uno de los más célebres articulistas científicos, colaborador permanente de la revista mensual Scientific American con su resonado escrito Juegos matemáticos y autor de más de cuarenta libros, trae en su colección de ensayos Los porqués de un escriba filósofo, las conclusiones a las que ha llegado sobre la fe, la inmortalidad, el mal, la sorpresa, la libertad, la plegaria y la ciencia, entre otros temas, siempre desde una negación que suscita la investigación y la respuesta. Por ejemplo, en el tema de la Ciencia, plantea "por qué no soy paranormalista", tratando de demostrar por qué no es válido serlo y por qué sí, a través de un método que recuerda la disertación: el sí, el no y la conclusión.

En un claro desarrollo del estricto marco Quintiliano de la proposición, la peroración y el epílogo, Gardner juega con las palabras y los conceptos. Al referirse a la ciencia como la "búsqueda de conocimientos fidedignos acerca del mundo" y a su división "en tres grandes apartados: hechos, leyes y teorías" afirma que no se puede explicar nada de ello si no es a través de las palabras, hablando y escribiendo. En la cita genial de este apartado, no podría apartarse de Paul Karl Feyerabend y su anti-método, desde el cual se contempla que para entender lo científico hay que ir a "Ia astrología, la parapsicología, el creacionismo, el vudú y las danzas de la lluvia" (Gardner, s.f., pp. 53-71).

Cualquiera que sea la interpretación del fenómeno, ésta supone un medio de divulgación, una diseminación, una socialización. Los babilonios se valieron de sus tablas, los egipcios de sus jeroglíficos, sus tratados y sus monumentos, los griegos hicieron otro tanto. Ellos tenían como referentes la mitología, la religión, la naturaleza, el hombre. Nosotros, en la investigación, estamos supeditados a otro elemento determinante: la ciencia y su consecuente inmediato, el medio que la socializa, ganando por bastante ventaja, el artículo cien- 
tífico, en el que se da fe y se visualiza lo investigado, lo descubierto, el avance e inclusive el horizonte.

Para mostrar la creación, pensar, hacer y sentir utilizamos la escritura, la pintura, los diagramas $y$, ahora las múltiples formas de expresión mediada. Las anchas autopistas informativas reciben todos los mensajes que ponemos. El arte, la ciencia, el lenguaje social, las manifestaciones cotidianas se plasman de una y mil maneras; se habla de la visibilidad como un elemento clave del progreso, como una forma de reconocimiento de lo existente en cualquier plano. En el argot comercial se dice que "si no se muestra no se vende", de ello cunden los ejemplos; la ciencia no podía ser ajena a este presupuesto y ha entrado en la carrera desenfrenada por mostrar lo que se hace; de igual manera, expresiones artísticas como la literatura y otras manifestaciones humanas hacen eco de dicho presupuesto.

En los procesos investigativos se ha entronizado la referencia que se ha vuelto, prácticamente, una ley de sobrevivencia "Io que está escrito existe, lo que no, no existe". El artículo científico se ha vuelto el tirano que se alimenta y se retroalimenta a sí mismo y da las pautas de calificación para el avance, el detenimiento o el retroceso de la ciencia. Extrañamente, aún subsisten científicos que no se preocupan por hacer conocer sus descubrimientos, por mostrar lo que hacen, por hacerlo visible.

\section{Epílogo. Tierra e invisibilidad}

Una de las más grandes fantasías del ser humano es poder estar en distintos sitios, particularmente sin ser visto, ser como los dioses iquién, por ejemplo, no ha querido saber qué hace su amada?, ¿en dónde se encuentra un ser querido?, ¿acompañar a la persona en su travesía, en sus avatares? Quizás gastar alguna broma o sacar de un apuro, vivir alguna experiencia o simplemente sentir el aire fresco de un susurro, de un beso de alguien, sin estar presente, pero estándolo. Desde los más remotos orígenes, el hombre ha querido ser inmortal, volar o simplemente ser invisible, probablemente para arreglar el mundo, para dominarlo, en suma para tener el poder de la divinidad.

En la Invención de Morel, la obra inmortal de Adolfo Bioy Casares, esta realidad se hace patética. La imposibilidad de su protagonista por alcanzar su producto científico, por acercarse a la otra vida, a la de Faustine y sus amigos, al amor, a la vida, tiene un sino trágico. El invento científico, la máquina capaz de crear otra realidad, es la misma que llevará al desasosiego, a la locura a quien hace parte del juego. Es fácil hacer un parangón con el poder invisible de la informática y la virtualidad, aunque la novela fue publicada en 1946 y todavía estaba lejos el poder absoluto de las autopistas informáticas.

En el mito griego, Hades "el invisible", hijo de Cronos y de Rea, no por azar hijo del tiempo, preside lo que ya pasó y no subsiste o no puede volver a existir y medita sobre lo posible, probablemente lo que no existe y lo que nunca será. En su reino lo visible se puede hacer invisible y viceversa, exactamente la tragedia de Orfeo y Eurídice, tenerlo todo y no tener nada, ver y no ver, hacer investigación y ciencia y no socializarla, difundirla, hacerla de todos.

Al comenzar esta disertación formulábamos una pregunta interesante ipor qué la Tierra es redonda? La respuesta es compleja y la han tratado desde los presocráticos hasta los múltiples pueblos indígenas de los diversos continentes. Los pedagogos y los diversos investigadores se han tratado de acercar a la respuesta más convincente. Quino, el genial humorista argentino, pone en boca de sus maravillosos personajes el interrogante y lo convierte en un leit motiv de toda su obra. En una de sus tiras cómicas, quizás la que más trascendencia y visibilidad le dio, Mafalda, nos trae a cuento el aula de clase, precisamente, el sitio donde la investigación, la ciencia y sus cuestionamientos deben -o deberían- tratarse. Al frente del salón, la maestra cuenta cómo Cristóbal Colón trasegaba en pos del cumplimiento de su ideal y que "pese a las burlas y a la incomprensión de todos, seguía afirman- 
do que la Tierra era redonda". Bien atrás de la fila de sus compañeros, Manolito con una sonrisa irónica y triunfal exclamaba: "¡Redonda...! ¡Qué bruto!". Quino da una lección de visibilidad, de cómo mostrar el mundo a través de una tira cómica. Disquisiciones como la planteada dan para un tratado extenso con los comentarios y las pruebas más disímiles. Ojalá que podamos tener la respuesta más fácil y contundente cuando la pregunta sobre el porqué de la redondez de la Tierra sea formulada por un niño.

Por su parte, la editorial Marvel comics constituye una muestra palpable de la lucha por hacer visible lo invisible, por llevar a diversos públicos su creatividad, sus personajes, sus formas legendarias y cómicas de ver la vida. Con un sentido ideológico y económico comenzó su trasegar por el mundo en 1939 y llegó a los países de habla hispana a través de la Editorial Novaro en México y de Ediciones Vértice y luego de la Editorial Bruguera, en España. Así fueron conocidos diversos personajes que poblaron la mente infantil y juvenil durante varias décadas: el Capitán América, Los cuatro fantásticos, la Antorcha humana, Spiderman, los Looney tones, Ghost rider, entre otros.

En medio de estos personajes un ícono de la invisibilidad de la ciencia se encuentra recreado metafóricamente con Susan "Sue" Storm, la mujer invisible. Esta heroína quien, de múltiples maneras, rige el destino de los cuatro fantásticos y se enfrenta a miles de obstáculos con el propósito de salvar el mundo, simboliza la mirada altruista de ver la ciencia, como el nuevo mito, como la salvación. En este punto, se podría entrar en mayores detalles, al aludir a las mujeres científicas invisibles, a aquéllas que no alcanzaron un grado de visibilidad o que el tiempo, las circunstancias y alguno que otro elemento las sumergieron en el olvido. La lista se puede hacer larga, sólo nombraré a Emilie de Breteuil o Emilie du Chatelet, una verdadera científica del siglo XVIII, la mujer amada por Voltaire y con quien se casó, la misma que tradujo y dio a conocer por primera vez al francés los Principia de Newton, aquélla que, según el físico y matemático David Bodanis, profundo estudioso de la energía y del universo eléctrico, se había adelantado al mismo Einstein, en su concepción de la energía, llevando sus trabajos, por ejemplo a "una variante del experimento de oxidación de Lavoisier, y si las balanzas que utilizaba hubieran sido algo más precisas podría haber sido ella quien descubriera la ley de la conservación de la masa, antes incluso de que Lavoisier hubiera nacido" (Bodanis, 2005, p. 78).

Un investigador que se pudiera situar en el siglo XIX, podría seguir los adelantos científicos, sin mucho esfuerzo, tanto como lo podía hacer, en la misma época, un estudiante no muy aventajado. Un científico bien podía ser a la vez geómetra, astrónomo, filósofo, ingeniero. En la actualidad es difícil congregar varias disciplinas en una sola persona, además que un hombre muy estudioso, difícilmente puede incursionar en todos los campos de la nanotecnología, por ejemplo. Unida a esta dificultad se encuentra la del analfabetismo científico, la de no querer enterarnos de los descubrimientos, de las investigaciones y mucho menos de intervenir en ellas. En Latinoamérica y, particularmente en Colombia, se estudia para tomar algunos elementos de alguna disciplina y aplicarlas en un puesto de trabajo, en el mejor de los casos, la mayoría de las veces para no aplicar nunca lo aprendido; no se estudia para buscar respuestas a problemas palpables del medio. En este mismo plano, tampoco se comunican los adelantos que se van haciendo. Es mejor hablar de política, de algún deporte y estar enterado de los chismes sociales y de los últimos acontecimientos de la farándula que de las incidencias de la radiactividad en nuestro contexto, de la importancia del hidrógeno en la energía o, sencillamente, de las mejores formas de eliminar las basuras en una urbe.

Al abordar los medios y las mediaciones que hacen que la ciencia y la investigación se difundan, bien podemos acudir al llamado periodismo científico, bastante escondido y subvalorado. Las colecciones científicas, los libros de investigación específica tienen altos costos económicos y no representan mayor interés para las editoriales, amén de los programas científicos, de las páginas que en las autopistas de la 
información quieren abrirse campo, de una que otra película y de algunos programas que pretenden cubrir estas falencias. Pero, lo más doloroso para los investigadores que pretenden divulgar un acontecimiento científico o investigativo es enfrentarse a un muro infranqueable lleno de desinterés y sin una puerta de salida. Tenemos que aprender a diferenciar entre los gestores de la investigación, los investigadores en sí mismos y los difusores y diseminadores de la ciencia.

En la práctica y en el diario trajín esto no es fácil, queremos meter a todo el mundo en la misma bolsa y eso nos regresa a la caja de Pandora y al ingenuo Epimeteo. Todo está ahí, la labor es ardua. Ahora no sólo tenemos que buscar qué investigar, sino también dónde, para qué, por qué y otro sinnúmero de interrogantes, en especial aquéllos cuya respuestas lleven a mostrar, enseñar y llevar a todos lo investigado, lo descubierto. Muchos científicos coinciden en que la ciencia es "saber ser y saber estar" y el tiempo nos ha enseñado que esta premisa, en cualquier caso apunta al saber pensar, saber actuar y, ante todo, saber expresar. Si para los profesores y los investigadores había un reto: investigar, ahora se abre otro, con mayor inclinación: escribir y difundir lo investigado, al fin y al cabo: ver o no ver, he ahí el dilema.

\section{Referencias}

Anónimo. (1978). Las mil noches y una noche. Barcelona: Círculo de lectores.

Asimov, I. (1985). Introducción a la ciencia. Barcelona: Ediciones Orbis.

Asimov, I. (1994). La última pregunta y otros cuentos. Barcelona: Ediciones B.

Bodanis, D. (2005). E=mc ${ }^{2}$. La biografía de la ecuación más famosa de Einstein. Barcelona: Editorial Planeta.
Bruce, C. (2004). Los conejos de Schrödinger. Física cuántica y universos paralelos. España: Ediciones de intervención Cultural/Biblioteca Buridán.

Cajas, F. Alfabetización científica y tecnológica: la transposición didáctica del conocimiento tecnológico. La Asociación Americana para el Avance de la Ciencia (American Association for the Advancement of Science) de los Estados Unidos (AAAS), Washington, D.C. Recuperado el 5 de octubre de 2008 de: www.raco.cat/index.php/Ensenanza/ article/view/21737/21571 -2k

Chan L.; Kirsop, B. \& Arunachalam, A. Revista peruana de Biología. Recuperado el 14 de octubre de 2008 de: http://sisbib.unmsm.edu.pe/BVrevistas/ biologia/.

Gardner, M. (1989). Los porqués de un escriba filósofo. Barcelona: Tusquets Editores.

Hawking, S. (2004). A hombros de gigantes. Las grandes obras de la física y de la astronomía. Barcelona: Crítica, S.L.

Hawking, S. \& Mlodinow, L. (2007). Brevísima historia del tiempo. Barcelona: Crítica.

Hirschberger, J. (1977). Breve historia de la filosofía. Barcelona: Editorial Herder.

Ouellete, J. (2007). Cuerpos negros y gatos cuánticos. Bogotá: Grupo Editorial Norma.

Parra R., O. (2008). El placer de investigar. Bogotá: Universidad Santo Tomás.

Revista Science. ¿Qué no sabemos? Science presenta los grandes misterios científicos no resueltos de nuestra época. Edición especial, $12^{\circ}$ aniversario. Recuperado el 12 de octubre de 2008 de: www.eurekalert.org/staticrel.php?view=aaftwdw062405sp. 


\section{Universidad Santo Tomás}

Sábato, E. (2000). El escritor y sus fantasmas. Bogotá: Planeta Colombiana Editorial.

Salazar, P. (18 de octubre de 2008). Apoteosis de Coelho en Francfort El Tiempo, sección 3, p. 1.
Vernant, J.P. (1985). Mito y pensamiento en la Grecia Antigua. Barcelona: Editorial Ariel. 